\title{
"Skaz" e o Cotidiano: a Influência do Jornalismo Russo do Final do Século XIX na Prosa de Nikolai Leskov
}

\author{
Fabrício Yuri de Souza Vitorino ${ }^{1}$
}

\section{Resumo/Abstract:}

O objetivo deste trabalho é traçar um panorama histórico do cenário editorial na Rússia durante a segunda metade do Século XIX, no qual se insere a obra de Nikolai Leskov. Com base nestes dados e de uma breve análise biográfica do autor, serão mapeadas algumas marcas de sua relevância crítico-jornalística em sua obra literária.

This paper aims to trace an historical panorama of the editorial scenary during the second half of the nineteenth century in Russia, in which is included the literary works of Nikolay Leskov. Based upon these data and a short biography of the russian author some marks of his critical jornalistic relevance contained in his artworks will be pointed out.

Keywords: Leskov, russian literature, russian journalism Palavras-chave: Leskov, literatura russa, jornalismo russo, jornais russos

\footnotetext{
${ }^{1}$ Bacharel em Comunicação Social - Jornalismo pela Universidade Federal Fluminense; Bacharel em Letras Habilitação Português-Russo pela Universidade Federal do Rio de Janeiro; mestrando em Letras - Lingua, Literatura e Cultura Russa pela Universidade de São Paulo. fabyuri@gmail.com
} 


\section{Introdução: panorama do mercado editorial russo no fim do século XIX}

A segunda metade do século XIX caracteriza-se por um tempestuoso desenvolvimento da consciência capitalista na Rússia. A Reforma Camponesa de $1861^{2}$, na qual foi promovida a emancipação dos servos, deu o empurrão necessário para que a força produtiva nacional fosse posta em movimento. Com a mudança do regime de servidão, a indústria começou a se desenvolver com sucesso no país. A extração de carvão e ferro ganharam força, dando subsídios ao desenvolvimento e construção de estradas de ferro. Com isso, a grande circulação de mercadorias favoreceu o florescimento do acúmulo de capitais e o crescimento das cidades. Foi o fim das relações de troca de bens, inatas aos camponeses, que se tornaram, essencialmente, dependentes da moeda corrente.

Na segunda metade do século XIX, a Rússia passa por alguns processos muito importantes, ao mesmo tempo em que a vida, em comparação com a primeira metade do século, sofria profundas modificações. E, claro, paralelamente a isso, a esfera jornalística ganhava novos contornos, com novas exigências aos editores e redatores ${ }^{3}$. A novidade da "imprensa comercial" paulatinamente substituía os veículos impressos baseados apenas no "ideal" - cujo objetivo principal seria a educação social. No comando dos novos veículos havia uma classe de empreendedores, que ainda tentava unir as duas "gerações" de escritores, objetivando, claro, atingir a um maior número de leitores.

Uma das características desse processo migratório de ideias e objetivos foi a substituição das denominações dos periódicos. Antes tratados como "revistas" ou "almanaques", agora eram chamados de "jornal" ou "jornal diário", o que influenciaria em muito o mercado e, em pouquíssimo tempo, passaria a dominar o sistema, com tiragens que os editores das décadas anteriores, de 1860 e 1870, sequer poderiam sonhar. Dessa finalidade deriva a segunda característica marcante do processo: o surgimento de novos materiais e possibilidades técnicas na linha de produção dos veículos impressos, que permitiu a impressão diária e em enormes tiragens, baseando-se na lei capitalista que prega "quanto maior a tiragem, menor o custo" ${ }^{4}$.

A mudança se deu também na esfera da organização. Antes fragmentados, os periódicos passaram a ocupar espaços em prédios da capital já a partir da década de 1870 ("como o SPB

\footnotetext{
${ }^{2}$ A reforma, promovida pelo czar Alexandre II, significou a liquidação da dependência servil a que era submetido o campesinato russo.

${ }^{3}$ Istoria russkoi jurnalistiki XVIII-XIX vekov. (História do Jornalismo na Rússia nos séculos XVIII-XIX) Pod red. prof. A.V. Zapadova. CHAST" II

${ }^{4}$ Idem
} 
Vedomosti", o "Russkie vedomosti" e o "Golos"). Com isso, surge ainda os periódicos segmentados, orientados principalmente por preferências religiosas da época - sobre o que escrevem Dostoiévski, V. Solovióv, Rozánov e outros. A quantidade de jornais diários aumenta cada vez mais, abrindo um leque de opções e diversificando a prática jornalística, que agora passa a ser dividida em, essencialmente, três vertentes ${ }^{5}$ :

- Conservadora/Monarquista: "Rússkie Viéstnik", "Moskóvskoie Vedómosti", "Grajdanin", "Novoie Vriémia");

- Liberal/burguês: "Viéstnik Evropy", "Golos", "Sankt Peterbúrgskie Vedómosti", "Rússkie Vedómosti";

- Democratas: "Iskra", "Otetchiéstvennie zapiski", "Delo".

Enquanto os primeiros defendiam abertamente em suas páginas os interesses da monarquia e das camadas mais altas da sociedade, os últimos da lista eram ferozes opositores do regime, saindo a favor da classe menos favorecida, a dos trabalhadores. Entre os dois grupos rivais, havia mais numerosa, com ideais provincianos e edições para as "pessoas comuns". No segundo grupo incluíam-se, ainda, humoristas, teatrais, esportivos e semanais ilustrados -, que, aliás, mantinham-se a parte das questões políticas.

Dessa forma, o sistema da imprensa estava formado e organizado já no final do século XIX, baseado em órgãos de qualidade e voltados para grandes massas - mesmo aqueles que eram tidos como "especializados". Já havia, então, o conceito fundamental de que os jornais diários deveriam levar para o leitor o máximo de informações acerca da vida russa e estrangeira. "Novoe vriémia", "Rússki kurrier", "Sviet”, "Nóvosti dnia", "Rússkoe slovo", "Rússki listok", "Rossia" são os principais e mais lidos jornais da época, que ganham importância não só nacionalmente. Aos poucos eles foram se tornando referência para um mundo cada vez mais carente de notícias sobre o país do leste europeu que acabara de entregar ao mundo gênios da literatura e da crítica, além de fermentar ideias revolucionárias. Aliás, no campo da contrarrevolução surge também o jornal "Siélski Viéstnik", ou notícias do campo, de orientação exclusivamente governamental, com o objetivo de aplacar (ou mesmo redoutrinar) o trabalhador recém-liberado das obrigações servis.

\footnotetext{
${ }^{5}$ PROTASOVA, O. L. Istoria rossiskoi jurnalistiki (História do Jornalismo na Rússia) (XVIII - nachalo XX). TGGU
} 
Alguns jornais da época (e suas respectivas linhas editoriais) ${ }^{6}$ :

Moskóvskie viédomosti (1756 - 1917), de M. N. Katkov - Um dos mais influentes jornais de orientação monarquista. O periódico posicionava-se sempre a favor das forças governantes, criticava o marxismo e condenava o movimento operário. Tinha livre acesso às repartições públicas e aos órgãos públicos, além de circular entre os nobres e os mercadores. Katkov assumiu abertamente sua posição contra o fim da servidão e, durante todo o tempo, incitava o governo à repressão dos movimentos democráticos pelo país. Após a morte de Katkov, em 1887, o jornal passa a não mais exercer qualquer papel relevante na vida política russa.

Novoe Vriémia (1868 - 1917), de A. S. Suvorin - Jornal diário de orientação autoritária do movimento monarquista. Tornou-se muito popular na década de 1870 , período em que se destacou com coberturas sobre a guerra russo-turca, publicando boletins diários sobre as operações, as baixas e as perspectivas gerais do conflito. E isso se dava, claro, com o consentimento da monarquia, que abria espaço para que os oficiais transmitissem as informações aos editores. Ele foi, aos poucos, abrindo espaço para as críticas ao comando de guerra, ao passo que passou a dar muito espaço às "Belas Letras", como poesias e contos. Na virada para a década de 1880, assumiu um caráter excessivamente reacionário, defendendo os interesses da nobreza. Foi fechado durante a Revolução.

Sankt Peterbúrgskie Viédomosti (1728 - 1917) - O mais antigo jornal russo, de orientação liberal, apoiou a reforma do governo com eventuais artigos assinados por representantes da "Intelliguentsia Democrática". No entanto, não assumiu uma posição de defesa dos interesses do povo, mantendo uma relação muito hostil com os métodos revolucionários de guerra contra o absolutismo. Orgulhava-se de seu slogan "Nosso tempo não é de tarefas profundas".

Golos (1863 - 1884) - extremista, liberal, era um dos órgãos "oficiais" da oposição, cujo slogan era "Somos a favor de uma reforma profunda". Obviamente, não durou muito.

Rússkie Viédomosti (1863 - 1918) - O diário tinha como linha editorial a defesa da limitação do poder absolutista através do estabelecimento de uma constituição. Em suas páginas eram propostas ideias como a delimitação de empréstimos a abastados, o abrandamento das leis contraditórias que regiam a relação entre patrões x empregados na época. Publicou "Aventuras

\footnotetext{
${ }^{6}$ KATCHKAEVA, A. G. Rossiskie Imperii SMI. (Sistemas de Informação em Massa no Império Russo) 1998, n. 6, TGGU.
} 
com um subversivo", de Saltikov-Shedrin, e tinha em seus quadros colaboradores como G. I. Uspiénski, A. N. Plechiéev e A. P. Tchehov. Em 1891, Tolstói publica em suas páginas os artigos "Ajuda aos famintos" e "Pergunta medonha", nos quais denunciava as classes dominantes e sua culpa sobre a difícil situação do campesinato, e por conta das quais o jornal recebeu uma advertência formal do governo. Apesar disso, o Viédomosti era, sem dúvida, um dos jornais mais sólidos e respeitados do país, ocupando um lugar de destaque tanto no mercado quanto na opinião de seus leitores, em todos os círculos sociais - incluindo aí o judiciário, que o alimentava com histórias sobre crimes, incêndios, assassinatos e outras que despertavam o interesse do grande público.

Iskra $(1859$ - 1873) - Um dos mais importantes de sua geração por se tratar do primeiro jornal partidário (social-democrata). Era distribuído ilegalmente fora da Rússia e trazido de volta ao país por intermediários. V. I. Lênin participou ativamente de sua fundação e redação e ajudou a definir sua meta principal: tornar-se uma referência para o movimento operário, preparar o levante revolucionário e derrubar o absolutismo no país. Entretanto, o jornal rapidamente se tornou menchevique, abrandando assim sua agenda radical e forçando Lenin e os bolcheviques a organizar outro periódico.

Viéstnik Evropi (1866 - 1918) - Um dos mais respeitados e poderosos jornais da época, circulou mensalmente. Tinha orientação burguesa-liberal e amplo respeito dos intelectuais da época. Nele, nomes como Turguêniev, Gonchárov, Saltikov-Shedrin, Ostróvski, A. K. Tolstói, dentre muitos outros, publicaram importantíssimos contos e poesias. Outros tantos críticos literários, historiadores, juristas, economistas e acadêmicos participaram ativamente do Viéstnik Evropi ao longo de sua existência. O jornal era dividido em duas partes: a primeira dedicada às belas letras, com poesias e notas de cunho acadêmico. Já a segunda englobava o noticiário nacional e internacional, além de críticas literárias e bibliografias. O Viéstnik Evropi trouxe em suas páginas muitas traduções de autores consagrados, como Emile Zola. Era também um pujante porto para análises de questões sociais delicadas, como o campesinato, a servidão, o sistema judiciário, a economia, a reforma educacional e administrativa... Essencialmente, ficou marcado por atuar contra os revolucionários e seus métodos de luta, acusando-os de serem "inimigos do processo pacífico" ou "assassinos políticos". Acabou fechado pelos bolcheviques.

Ao passo que as condições industriais vão melhorando - inclui-se aí a melhora nas prensas, na qual ganha força a impressão policromática -, começam a aparecer os primeiros 
anúncios publicitários ${ }^{7}$, que, somados aos anúncios governamentais, passam a ser o principal meio de aporte de recursos dos jornais no final do século XIX. A partir daí, a antiga forma de negócios, na qual as revistas eram exclusivamente intelectuais, chega ao fim, dando lugar a um modelo de negócios, senão essencialmente capitalista, já especificamente condensador de um modelo informativo no qual o objetivo é atingir a massa, seja com ideias, seja com um produto.

Agora, o "periodismo" se tornara um negócio que contava com capital privado, que necessitava de uma gerência suplementar - surgem aí as "agências para divulgação da imprensa", ferramentas indispensáveis que visavam à publicação e distribuição fora das capitais. Com a concorrência cada vez mais ferrenha, estar em mais lugares e atingir mais públicos se tornara essencial para a sobrevivência do negócio.

No entanto, é no final dos anos 1870 que uma prática até então sempre descartada pelos editores passa a se tornar recorrente nos jornais: a publicação de artigos sobre crimes e notas sobre julgamentos. A partir da comoção, o que antes era considerado "material trivial", que não ajudaria na função social do jornal, passou despertar enorme interesse público e se tornar indispensável à linha editorial dos periódicos - sob pena da perda de leitores que, ávidos, buscavam cada vez mais tal material com forte apelo moral e emocional. A partir daí surgem também as chamadas "reportagens especiais". Reminiscências sobre crimes antigos, biografia de foras da lei, detalhamento de processos jurídicos, tudo o que fugisse à norma social era história e encontrava eco na curiosidade ávida (e por vezes mórbida) dos leitores. Além da seção "criminal", também ganharam força os pequenos contos e os folhetins, que se tornam sobremaneira populares.

Deste modo, o fim do século na Rússia marcou a coexistência e a transição do antigo formato das "revistas" para os jornais, consolidando, assim, o entendimento do "sistema de informação massiva", que delimita o recém-formado mercado de produção de notícias.

No entanto, um grave defeito permanece ao longo de todo o século XIX - e viria a perdurar ainda por muitas décadas: a inexistência de uma imprensa livre e demais liberdades políticas ${ }^{8}$.

É nesse cenário caótico, intenso e pujante nas artes mas pobre em direitos, que se destacam, inicialmente, A. S. Púchkin, N. V. Gogol, F. V. Bulgarin, Tolstói, F. M. Dostoiévski,

\footnotetext{
${ }^{7}$ idem

${ }^{8}$ SCHNAIDERMAN, Boris. Os escombros e o mito: a cultura e o fim da União Soviética. São Paulo, Cia. das Letras, 1997.
} 
N. A. Nekrásov, A. A. Delvig, A. I. Herzen, dentre muitos outros. E Nikolai Semiónovich Leskov. 


\section{Vida e obra de Nikolai Leskov}

Nikolai Leskov nasceu em fevereiro de 1831, em Gorochev, uma pequena cidade da região de Oriol, a sudoeste de Moscou. Pouco mais jovem que Dostoiévski e Tolstói, era bastante diferente de seus contemporâneos. Nascido e educado em uma família nobre, levou uma vida confortável até a morte do pai. A partir daí, um fogo consumiu as propriedades da família, arruinando suas finanças e pondo fim ao sonho de uma educação completa.

Desde pequeno, nunca deixou de manter contato com os camponeses. Ouvia suas pequenas histórias, atento aos dramas e aos acontecimentos simbolicamente fantásticos. Acabou para sempre inspirado tanto pelo que ouvia quanto pelo que via. Seus ouvidos moveram sua pena, enquanto seus olhos, que acompanhavam atentos o trabalho braçal dos menos favorecidos, transformaram sua literatura, que passou a ser disciplinada e "braçal". "Escrever, para mim, não é uma arte liberal, mas um ofício"" ${ }^{9}$, afirmou certa vez em carta.

Tal simpatia com os camponeses o fazia identificar-se com Tolstói, enquanto no campo religioso aproximava-se de Dostoiévski. No entanto, sua ausência de títulos em educação formal o afastava da cena literária da época, bem como sua acidez nas críticas à burocracia da igreja faziam dele um completo renegado. Leskov foi um contador de histórias, acima de tudo. Mas que utilizava recursos estilísticos que o aproximavam tanto do romance - num aspecto por vezes fantástico e místico - quanto do jornalismo, ao reproduzir, por vezes fielmente, a linguagem coloquial das classes mais baixas ${ }^{10}$.

Leskov utilizava, em suas narrativas, a técnica conhecida como "skaz"11 (conto), na qual a "voz" do narrador (ou contador) não é aquela do autor. Acusado de ser um conservador, vivia entre o idealismo e a relidade (tema de sua primeira novela, "Nekudá"). E, se já era malvisto nos círculos literários, após a publicação de "Na nojah"12, acabou definitivamente banido deles. Sem periódicos para publicar suas histórias - os liberais já lhe haviam virado as costas -, Leskov se

\footnotetext{
${ }^{9}$ O próprio Leskov considerava essa arte artesanal - a narrativa - como um ofício manual. "A literatura", diz ele em uma carta, "não é para mim uma arte, mas um trabalho manual." Walter Benjamin. In O Narrador

10 "Nas lendas russas, Leskov viu aliados em sua luta contra a burocracia ortodoxa. Há uma série de seus contos lendários cujo foco é o homem justo, raramente um cético, em geral um homem simples, ativo, que se torna um santo, aparentemente da forma mais natural no mundo. A exaltação mística não é o forte de Leskov, mesmo que ele ocasionalmente gostasse de entrar no 'milagroso'. Ele vê o protótipo do homem que encontra seu caminho sobre o mundo sem ficando muito profundamente envolvido com isso." Walter Benjamin. In O Narrador

${ }^{11}$ CORNWELL, Neil. Skaz Narrative. The Literary Encyclopedia. 2005.

${ }^{12}$ Em tradução livre, em pé de guerra.
} 
volta para os conservadores. No entanto, suas fortes críticas à igreja também ajudaram a fechar portas.

Já no final da década de 1880, tutorado por Lev Tolstói, Leskov publica uma série de artigos sobre mitos antigos da igreja que, obviamente, acabam atraindo atenção da censura. Cada vez mais contumaz, Leskov se vê completamente tolhido, sem ter onde trabalhar - ou mesmo divulgar seu ofício.

Ao fim da vida, com câncer, Leskov era tratado pela intelliguentsia como reacionário e malvisto pelos conservadores, pela nobreza e autoridades religiosas. Sete anos após sua morte, em 1895, em São Petersburgo, seus trabalhos são publicados pela primeira vez reunidos. Ainda que grandes nomes das artes, como A. P. Tchekhov, Maksim Górki ${ }^{13}$, Boris Eihenbaum, Andrei Biéli e Isaac Babel tenham sempre dado a ele os devidos créditos por influenciar toda uma geração de escritores, seus trabalhos continuaram banidos até a década de 1950, quando, enfim, seu trabalho passou a ser analisado e reconhecido mundialmente.

Nikolai Leskov encontra, na literatura, um refúgio ideal para suas habilidades narrativojornalísticas. É ali que ele, observador apurado do mundo, procura obter o eco necessário para o desenrolar de suas histórias - na verdade, todas elas com um fortíssimo cunho de crítica social. "Leskov está à vontade tanto na distância espacial como na distância temporal", explica Benjamin. "Seu ideal é o homem que aceita o mundo sem se prender demasiadamente a ele."

Não estivesse a Rússia, então czarista, vivendo um duradouro período de exceção, com a privação dos direitos e da liberdade de imprensa, Leskov certamente teria tomado outro rumo. Seu primeiro trabalho, "Por que são os livros caros em Kiev?", já indicava o rumo que seu ofício iria lhe abrir. "Seus contos foram precedidos por uma série de escritos sobre a classe operária, sobre o alcoolismo, sobre os médicos da polícia e sobre os vendedores desempregados", afirma Walter Benjamin. Uma contextualização indispensável, que coloca o leitor no centro da "urbi" leskoviana, seja ela onde for.

\footnotetext{
13 "Leskov é o escritor mais enraizado no povo e permanece intocado pela influência estrangeira", Boris Eihembaum. O proze (Sobre a prosa): — P. 358. Leningrad, 1969.
} 


\section{Marcas na prosa}

Encontrar exemplos da interseção interestilística na obra de Nikolai Leskov não é difícil. Tanto a narrativa romântica quanto o jornalismo histórico estão magistralmente combinados na obra do autor, e foram precisamente bem descritos por Walter Benjamin: "O narrador retira da experiência o que ele conta: sua própria experiência ou a relatada pelos outros. E incorpora as coisas narradas à experiência dos seus ouvintes." ${ }^{14}$

Dentre a obra traduzida de Leskov para o português, encontramos alguns bons exemplos que ilustram tanto a descrição sutil do cenário, lançando mão da reprodução prosaica da linguagem, quanto a descrição social velada, inerente ao crítico social já em "Kótin, o provedor, e Platonida".

Ele estava disposto a tudo para secá-las, mas o que podia fazer por alguém? Ele, um mendigo, um aleijão, um feioso. (...) "Pelejar com ela no tribunal", pensou Pizónski, "leva muito tempo, e eu não tenho dinheiro para isso, e, até que ordenem que me entregue as crianças, ela já terá cegado as duas". (Leskov, 2012, 17)

Para descrever um personagem de seu conto, Leskov abre mão do estilo, da sutileza da língua e do código de belas letras que vigora entre seus contemporâneos. É necessário criar essa empatia com o leitor, é necessário um tipo popular, já que se trata de uma cena popular. Desse modo, "aleijão" e "feioso" passam a integrar o léxico, num exemplo claro da submissão do autor à compreensão e à contextualização. Enquanto outros contistas se preocupam, deveras, com a forma, Leskov trabalha em função do "skaz". Ele é um mero trabalhador braçal, que precisa utilizar quaisquer recursos que sejam necessários para atingir a tão almejada verossimilhança.

Em seguida, no raciocínio de seu personagem, Leskov embute uma crítica - entre muitas - ao sistema judiciário russo da época, notadamente burocrata e favorecedor, dependente de caminhos escusos para que a justiça seja feita. "Pelejar com ela no tribunal leva muito tempo" cria, automaticamente, uma empatia com um leitor que pensa exatamente da mesma forma. No entanto, sua crítica não encontra eco nos jornais e revistas da época.

Em "Voz da Natureza" há outro exemplo de como a pena leskoviana pode ser sutil ao retratar a realidade e, ao mesmo tempo, introduzir o leitor em um universo literário pouco comum: aquele inspirado na realidade da vida do cidadão comum. O príncipe Bariátinski é

\footnotetext{
${ }^{14}$ BENJAMIN, Walter. O Narrador: considerações sobre a obra de Nikolai Leskov. In: Magia e técnica, arte e política: ensaios sobre literatura e história da cultura. São Paulo: Brasiliense, 1994, p. 197-221.
} 
recebido pelo cidadão comum Filipp Filípov, envolvido em um clima de mistério acerca de uma dívida de gratidão. Leskov, usando do artifício de repetir uma história que lhe foi contata remetendo à tradição das narrativas orais clássicas -, assume o papel de contador de histórias. Ele envolve o leitor com um vocabulário trivial, com situações cotidianas, e abusa dos diminutivos, que, notadamente, têm por objetivo aproximar o leitor e minimizar a vida de Filípov diante de toda a grandeza do nobre marechal de campo. "Vodcazinha", "daminha", “bonitinha"..., o arsenal de Leskov é simples e eficaz. O leitor já está envolvido quando se vê diante do diálogo de uma bela jovem com Bariátinski:

- E os nossos escritores russos, não os lê?

- Não - respondeu ela -, não leio.

- E por quê?

- Eles quase não falam das coisas da alta sociedade

- E você gosta das coisas da alta sociedade?

- Gosto

- E por quê?

- Porque da nossa própria vida já sabemos, a dos outros é muito mais interessante.

(Leskov, 2012, 98)

Ora, se não é exatamente essa a grande chave de leitura de um bom conto, de uma boa história, e que perdura através dos séculos? Até os dias atuais, a vida alheia, o saber como vivem as classes "superiores", exerce um enorme fascínio no leitor cotidiano. Novamente, recorrendo ao texto "O Narrador"15, de Walter Benjamin, a empatia se dá pela simplicidade. E a crítica aos costumes de então - sobretudo aquele de ignorar os escritores nacionais em função de uma literatura rasa, porém garantida de status por ser "estrangeira" - se dá claramente. "Quanto maior a naturalidade com que o narrador renuncia às sutilezas psicológicas, mais facilmente a história se gravará na memória do ouvinte."

Por sua vez, em "A Fraude", mais uma vez Leskov recorre ao que Benjamin bem esclarece: "A experiência que passa de pessoa a pessoa é a fonte a que recorreram todos os narradores. E, entre as narrativas escritas, as melhores são as que menos se distinguem das histórias orais contadas pelos inúmeros narradores anônimos" (Benjamin, 1994, 2). Logo no início de seu conto, Leskov assume o papel de narrador-ativo, embora ainda longe dos padrões teatrais recorrentes, e já inicia com uma virulenta, ainda que cotidiana, crítica ao sistema:

Falávamos da fraqueza de caráter dos russos, da insuficiência de rigor em alguns órgãos do poder, do classicismo e dos judeus. Acima de tudo, voltávamos as

\footnotetext{
15 idem
} 
nossas preocupações para como fortalecer o poder e dar cabo dos jides, caso não fosse possível endireita-los, e como conduzi-los, no mínimo, até certo grau de nosso próprio nível moral. (Leskov, 2012, 101)

Aqui, Leskov dá início a uma abordagem sistêmica sobre a problemática dos judeus na Rússia. Tal estudo culminou com o artigo "O judeu na Rússia: notas sobre a questão judaica" 16 , escrito em 1883 e divulgado apenas entre os órgãos designados para analisar os sucessivos pogroms no sul da Rússia, nos anos de 1881 e 1882. O artigo foi banido e, somente após o fim da União Soviética, nos anos 1990, foi publicado e veio ao conhecimento do grande público. Nele, Leskov mostra que não só domina todas as nuances da vida dos judeus em "todas as Rússias", como também derruba mitos. Para ele, não só o habitante da "Pequena Rússia", como era conhecida a Ucrânia, vive melhor do que qualquer conterrâneo da "Grande Rússia", como os judeus, "perigosos ou não", exercem pouca ou nenhuma influência, para bem ou para mal, em qualquer aspecto da vida cotidiana.

O mito dos judeus, trazido à tona em "A Fraude", é de um poder avassalador na mente do leitor de Leskov da época. Segundo a crença de então, o judeu "é uma ameaça constante a seu bom vizinho cristão trabalhador", e ele aponta que isso é mesmo ensinado em escolas e igrejas. No entanto, Leskov abandona os paradigmas etnográficos e relembra o clássico ditado popular: "Um cigano irá enganar um camponês, um judeu vai enganar um cigano, um armênio vai enganar um judeu, um grego vai enganar um armênio e somente um demônio pode enganar um grego, se assim Deus permitir”, para embasar sua defesa. Até mesmo nas crenças populares, o judeu não seria o "pior elemento". "O indiciamento dos judeus é altamente questionável. E é inaceitável que ainda se fale que 'o judeu recruta cristãos para sua própria fé e estraga sua ortodoxia'. Isso jamais aconteceu com judeus", resume, antes de concluir que "O que vem acontecendo com o judaísmo nos últimos anos é o sumário abuso de pessoas - os helênicos e os judeus".

Ainda em "A Fraude", Leskov aproveita para lançar uma reflexão acerca do papel que as mulheres vêm assumindo frente à sociedade em franca transformação.

No nosso tempo, as mulheres não tinham os sonhos de independência de hoje, que, a propósito, eu não condeno, porque há maridos completamente impossíveis, de modo que a fidelidade a eles pode até ser pecado. (...) Os casamentos então

\footnotetext{
${ }^{16}$ Evrei v Rossii. Neskolko zamechani po evreiskomu voprosu. (Judeus na Rússia: algumas impressões sobre a questão judaica) Moskva, Kniga, 1990.
} 
eram apenas normais, verdadeiros, cantados na igreja e por costume depois deles não se proibia o amor livre a militares. (Leskov, 2012, 107)

A temática da mulher, abordada de forma rasa aqui, é aprofundada na obra-prima "Lady MacBeth do Distrito de Mtzensk”. Nesta novela, dramática e sombria, o tédio e as inquietações de Katierina Lvovna dão voz ao sofrimento de milhares de mulheres da sociedade de então. Casada com um senhor de terras mais velho, tedioso e pequeno-burguês, Lvovna é enclausurada em sua casa e, incapaz de dar ao marido um filho, é culpada pela infertilidade pelos pares sociais. Ao surgimento de seu amante, e das escabrosas mazelas de ambos, segue-se um hediondo crime, para o qual a punição é o envio para campos da Sibéria.

Nada foge à pena atenta de Leskov. Nenhum tema estará intocado, ou mesmo mal abordado, tendo em vista a máxima de que, se um assunto é do povo, pertence à literatura. Como bem definido por Elena Vássina, "O verdadeiro talento de Leskov revelou-se em suas narrativas curtas, aquelas que refletiam seu conhecimento, profundo, variado e amplo - como as estepes que ele tanto percorreu - da vida russa, de todas as diversas camadas de sua população e dos tipos humanos que nunca eram enxergados pela literatura até então" ${ }^{17}$.

\footnotetext{
${ }^{17}$ LESKOV, Nikolai. A Fraude e outras histórias. Tradução de Denise Sales. 'O mais original dos escritores russos'.
} Vássina, Elena. São Paulo, Editora 34, 2012. 


\section{Conclusão}

A genialidade de Leskov é percebida justamente na sua simplicidade, na modéstia de seus narradores e na impotência diante da arte narrativa. E sua grande contribuição, tanto para a literatura quanto para a crítica social, reside no fato de que, como definiu Elena Vássina, ele “consegue reproduzir o amplo panorama da vida russa não em romances, que era o gênero principal na literatura clássica russa do século XIX, mas em crônicas, contos e pequenas novelas que, na obra do escritor, formaram um sistema único de narrativa" ${ }^{18}$.

Mais de cem anos depois, pode-se dizer sem medo de errar que Leskov, não obstante a grandeza de seu trabalho, fez tudo errado. Provocou a ira dos niilistas, foi eclipsado por Tolstói e Dostoiévski, jamais manteve uma visão totalizadora, foi o grande ícone do "skaz", enveredando por narrativas granuladas e com heróis desprovidos de heroísmo. Sua fixação pelos "homens justos" criou uma mistura de confusão com inocência que até hoje encanta e intriga seus leitores, detratores e estudiosos. Leskov simplificou a narrativa realista e, em vez de descrever os pormenores, generalizou padrões e cenários. Em sua obra, a frase cotidiana, que repetimos quando algo fora do normal acontece - "foi como nas novelas" - ganha vida, numa curiosa inversão de papeis. O fantástico vira trivial. E o trivial passa a entreter.

Curiosamente, o que ainda há que ser pensado na prosa leskoviana é que a malha narrativa é muito mais importante do que todo o cenário e artimanhas discursivas. $\mathrm{O}$ talento de Leskov - e seu encantamento - são prosaicos, mas atraentes. E isso é uma consequência do meio em que viveu, da censura, da supressão de direitos e perseguição política.

A história da Rússia, conturbada e cheia de conflitos, sempre apontou um caminho diferenciado para seus artistas. Na impossibilidade de dar voz a seus pensamentos e críticas, estas encontram refúgio na literatura, no cinema, na pintura, na música. Enquanto as válvulas de escape mais óbvias estão severamente vigiadas (como os jornais e as revistas), os contos, os romances, as poesias, etc. servem como retrato fiel de posições, de conflitos e de resoluções.

Citando Boris Schnaiderman, "se tivesse de indicar aquilo que a literatura russa apresenta de mais característico e que lhe dá um toque peculiar, eu apontaria para a oscilação entre o ficcional e o histórico. (...) E isso nos obriga a repensar um dos aspectos essências da literatura russa: o balancear entre a ficção e o documento. Reconhecê-lo não significa de modo algum

\footnotetext{
18 idem
} 
advogar a sujeição da primeira ao segundo, que seria simplesmente detestável, mas admitir a importância da fronteira entre os dois, do limiar em que ambos se tocam" 19 .

E Leskov era um homem de limiares. "Metade da arte narrativa está em evitar explicações", conclui Walter Benjamin. Enquanto toda a ação é narrada ao leitor, este está livre para decidir todo o resto, não explícito na informação. Saber informar é um talento. Mas saber o que não informar é algo extraordinário. E nisso Nikolai Leskov foi um grande mestre.

${ }^{19}$ SCHNAIDERMAN, Boris. Os escombros e o mito: a cultura e o fim da União Soviética. São Paulo, Cia. das Letras, 1997. 


\section{Referências bibliográficas}

Benjamin, Walter. “O Narrador: considerações sobre a obra de Nikolai Leskov”. In: Magia e técnica, arte e política: ensaios sobre literatura e história da cultura. São Paulo: Brasiliense, 1994, p. 197-221.

Eihenbaun, Boris. O proze. (Sobre a prosa) - S. 346-356. N. S. Leskov, K 50-letniu so dniá smerti (N. S. Leskov: aos 50 anos de sua morte). Leningrad, 1969.

Lantz, K. A. Nikolay Leskov. Twayne's world authors series, TWAS 523: Russia. Boston: Twayne Publishers, 1979.

Leskov, Andrei. Zhizn' Nikolaia Leskova; po ego lichnym, semeinym i nesemeinym zapisiam i pamiatiam. Moskva: Khudozhestvennaia literatura, 1954. Often tinged

Leskov, Nikolai. Lady MacBeth do Distrito de Mtsensk (Trad.: Paulo Bezerra). São Paulo, Editora 34, 2008.

- Sobránie sotchiniénii v odínnatsati tomakh (Obras Reunidas em Onze Volumes). Moscovo, Editora Estatal de Belas Letras, 1958.

- Homens Interessantes e Outras Histórias (Trad.: Noé Oliveira Policarpo Polli). São Paulo, Editora 34, 2012

- A Fraude e Outras Histórias (Trad.: Denise Regina de Sales). São Paulo, Editora 34, 2012.

Mann I. V. Russkaia literatura XIX v.: Epoha romantizma (A literatura russa do séc. XIX: A época do romantismo), M., Aspekt-Press, 2006

Mclean, Hugh. Nikolai Leskov: The Man and His Art. Bridgewater, NJ: Replica Books, 2001

Muller de Morogues, Inès. "Le Problème féminin" et les portraits de femmes dans l'oeuvre de Nikolaj Leskov. P. Lang, 1991 
Sazonova, L. I. Literaturnaia kultura Rossii: ranee novoe vremia (Cultura literária na Rússia) M., 2006

Schnaiderman, Boris. Os escombros e o mito: a cultura e o fim da União Soviética. São Paulo, Cia. das Letras, 1997.

Sperrle, Irmhild Christina. The Organic Worldview of Nikolai Leskov. Northwestern University Press; 1 edition (March 13, 2002) 